\title{
A minireview of copper material applications in electrochemical sensing
}

Karolina Dziąbowska*1,2, Wioleta Białobrzeska ${ }^{1,2}$, Natalia Malinowska $^{1,2}$, Elżbieta Czaczyk ${ }^{1,2}$, Dawid Nidzworski1,2

${ }^{1}$ Institute of Biotechnology and Molecular Medicine, Gdansk, Poland;

${ }^{2}$ SensDx SA, Warsaw, Poland;

Corresponding author: karolina.dziabowska@etongroup.eu

DOI: 10.31708/v1.i1.Dbz2018

Keywords Copper, Copper oxide, Copper sensor, Electrochemical sensor, Copper electrode, Copper nanoparticles, Nanomaterials.

\section{Abstract}

Copper is an important metal in analytical and industrial fields as it has excellent thermal and electrical properties. In many disciplines, like electronics, optics, and others, copper nanoforms pay more attention than other noble metals nanoparticles. Attractive are its natural abundance, low costs and high activity toward many analytes with simultaneous physical stability. Extensive use has brought new types of sensors and practical implementations. The objective of this paper is to present crucial developments of copper material in the sensing field. Practical applications in the environmental section, like chemical oxygen demand measurement or carbon dioxide reduction reaction for atmospheric $\mathrm{CO}_{2}$ reduction; technological sensors like organic light-emitting devices, electronic tongue for alcohol type determination, human skin touch and move sensor; and medical sensors for glucose, alcohol, dopamine or paracetamol detection were presented.

\section{Introduction}

Copper (Cu) as conductive, transition metal is raising much interest in chemical sensing, mainly for electronic and optical use. Cu as a metal and metal oxides $\left(\mathrm{Cu}_{\mathrm{x}} \mathrm{O}\right)$ is more willingly used in nanostructure form as it provides signal enhancement, excellent electrical and optical properties, high catalytic activity, broad accessibility, and approximately low cost.

$\mathrm{Cu} / \mathrm{Cu}_{\mathrm{x}} \mathrm{O}$ applied to the electrode as nanoparticles (NPs) exceed enzymes and other biosensors due to extended activity, easy storage and temperature resistance. The wide range of modification methods, using different shapes and sizes of CuNPs and its derivatives, forming monolayers or more complex structures, open a new branch of sensors. (Li et al., 2015)

\subsection{Copper material characteristics}

Copper is commonly used in electrical contact and as an electrode in electrical discharge machining. It is used severally or in alloys like copper-tungsten. $\mathrm{Cu}$ is believed to be a better electrode than aluminum or brass, offers greater surface finish, higher electrical conductivity and resistance. (Singh et al., 2004)

Electronic properties of copper and copper oxides strongly depend on the size when functioning as NPs. In the nanosize range of $2-15 \mathrm{~nm}$, a smaller size $(<5 \mathrm{~nm})$ leads to higher catalytic activity towards $\mathrm{CO}_{2}$ electroreduction. $\mathrm{Cu}$ properties also vary through the dispersion on the electrode. (Reske et al., 2014) Typical structures are NPs with average size 20-100 nm, nanorods with 200-300 $\mathrm{nm}$ length, $\sim 150 \mathrm{~nm}$ width and $\sim 20-40 \mathrm{~nm}$ thickness, nanowires with an average diameter of $150 \mathrm{~nm}$ and length of $53 \mu \mathrm{m}$ or nanospheres, being single crystals of an average size of $23.4 \pm 1.5 \mathrm{~nm}$. (Sahai et al., 2016; Zuo et al., 2017; Dang et al., 2017; Tran et al., 2017; Guo et al., 2014) CuNPs have valuable physical properties- good electrical and thermal conductivity, light absorption with an absorption peak at $570-580 \mathrm{~nm}$. They are more reactive compared to other metallic NPs. (Tamilvanan et al., 2014; Wu et al., 2014)

Among various methods of NPs synthesis, electrochemical one raise much interest due to its simplicity and low costs. NPs are produced in situ in the electrochemical cell through metal ions reduction from the electrolyte onto electrode material by the applied potential. This approach is less labor intensive, reduces the number of reagents and time compared to standard laboratory synthesis. Also, there are fewer factors crucial for proper synthesis as most of the reactions occur in 
room temperature and last few minutes. Electrodeposition can be driven by parameters of electrolyte or the electrode substrate. (Balasubramanian et al., 2017; Yang et al., 2013) Parameters of the electrolyte are $\mathrm{pH}$, the concentration of NP precursors, temperature or applied potential. (Anand et al., 2015; Huang et al., 2005; Salehi, 2014) By this method, it is easy to control the NPs properties, like size and shape. Applying higher voltage causes smaller size and higher density of NPs as more nucleation sites are active. The kinetics of the process is also dependent on temperature: the higher the temperature, the bigger the NPs size and a smaller the amount of particles. (Q. B. Zhang et al., 2014)

$\mathrm{Cu} / \mathrm{Cu}_{\mathrm{x}} \mathrm{O}$ materials require alkaline conditions when used as enzyme-like sensing materials, where are electrochemically oxidized to $\mathrm{Cu}_{x} \mathrm{O} / \mathrm{Cu}(\mathrm{OH})_{2}$. Pure copper materials are low-conductive thus are coupled with different conductive materials, mainly carbon. (Xie et al., 2018) Examples of carbon materials for copper-based sensors are graphene, carbon nanoparticles, glassy carbon. (Jin et al., 2017; S. Wang et al., 2018; Lassègue et al., 2017; Tahir et al., 2018; Arévalo et al., 2017) There are also possibilities to combine copper with other metals (nickel, gold, palladium) forming alloy nanoparticles. (X. Ma et al., 2019; Shah et al., 2017; S. Liu et al., 2018)

Table 1 Copper material applications.

Several authors have studied characteristic of the metallic copper electrode. $\mathrm{Cu}$ electrochemistry in alkaline solutions is very complex as three oxidation states of copper occur: $\mathrm{Cu}(\mathrm{I}), \mathrm{Cu}(\mathrm{II})$ and $\mathrm{Cu}(\mathrm{III})$, in soluble and insoluble forms. Marioli et al. showed a full electrochemical scan of the copper electrode under alkaline conditions $(0.15 \mathrm{M} \mathrm{NaOH})$. (Marioli et al., 1992) The $i=f(E)$ characteristic ( $i$ - current density, E-potential) showed 7 peaks corresponding to: oxygen adsorption, $\mathrm{Cu}^{\%} / \mathrm{Cu}^{\prime}$ oxidation, $\mathrm{Cu} / \mathrm{Cu}^{\prime}$ and $\mathrm{Cu}^{\prime} / \mathrm{Cu}^{\prime \prime}$ transitions, soluble copper forms like $\mathrm{CuO}_{2}{ }^{2-}, \mathrm{Cu}^{\prime \prime \prime} / \mathrm{Cu}^{\prime l}$ reduction, $\mathrm{Cu} / \mathrm{Cu} / \mathrm{Cu}^{l}$ reduction, and $\mathrm{Cu}^{1} / \mathrm{Cu}^{0}$ transition. $\mathrm{Cu}(\mathrm{I})$ and $\mathrm{Cu}(\mathrm{II})$ are generated in the anodic scan. $\mathrm{Cu}(\mathrm{III})$ is generated close to oxygen evolution potential $(-0.6 \mathrm{~V})$, where its stability increases with the increase of $\mathrm{OH}^{-}$ions concentration. (Paixão et al., 2004)

\subsection{Copper applications in electrochemical sensors}

The main copper applications in electrochemical sensors were presented in Table 1.

\section{Copper material applications}

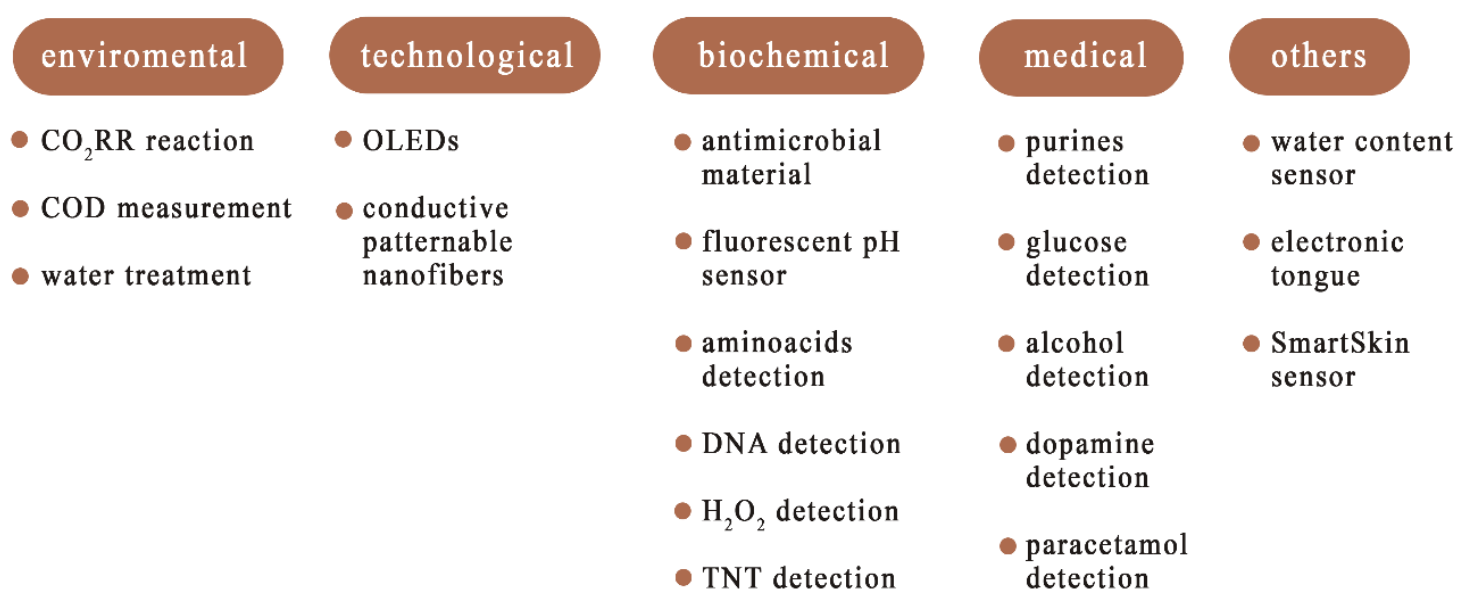




\subsubsection{Environmental and technological sensors}

Copper electrodes raise much interest in technological and environmental processes. Electrochemical carbon dioxide reduction reaction $\left(\mathrm{CO}_{2} \mathrm{RR}\right)$ to alcohols and hydrocarbons helps reduce atmospheric $\mathrm{CO}_{2}$ concentration. Producing fuels as methane or ethanol offloads fossil-fuels resources. (Rendón-Calle et al., 2018) Hori et al. first showed that electrolysis of carbon monoxide in aqueous solution is possible on $\mathrm{Cu}$ material forming methane, ethane, ethanol, formaldehyde and more. (Hori et al., 1987) The main disadvantages of $\mathrm{CO}_{2}$ electrolysis are low selectivity and high overpotentials. The reaction in aqueous media has many intermediate species like ${ }^{*} \mathrm{CO},{ }^{*} \mathrm{COH},{ }^{*} \mathrm{CHOH}$, ${ }^{*} \mathrm{CH}_{3}$ which in experimental techniques cannot be all characterized. Influential on the electrolysis performance is electrode structure, $\mathrm{pH}$, temperature, the applied voltage or current density. (RendónCalle et al., 2018) The biggest drawback is fast $\mathrm{Cu}$ deactivation, within $30 \mathrm{~min}$ of electrolysis, as copper oxidizes in oxygen access. Moreover, poor efficiency of $\mathrm{CO}_{2}$ reduction is due to the low solubility of $\mathrm{CO}_{2}$ carbon dioxide and high rates of hydrogen production. Thus, nonaqueous or mixed solvents are used. Acetonitrile is willingly used as preferred due to its high dielectric constant and four times higher $\mathrm{CO}_{2}$ solubility. In nonaqueous electrolytes, the main reaction product is $\mathrm{CO}$. (Jitaru et al., 1997) Oxidized copper surface can be regenerated by photothermochemical reduction using a laser beam. (Han et al., 2015)

Many articles proved that $\mathrm{CO}_{2}$ reduction occurs directly on the surface of $\mathrm{Cu}$. This process is very sensitive to the structure of the outer layer of the copper electrode. (Durand et al., 2011; Garza et al., 2018; C. Liu et al., 2012) For the polycrystalline copper, the different structure organization gives various products selectivity, as $\mathrm{CO}_{2} \mathrm{RR}$ is a structure-sensitive. Different atoms arrangement forces various adsorption and bonds breaking of the reactant. On $\mathrm{Cu}(111)$ facet methane is mainly produced, where $\mathrm{Cu}(100)$ yields ethylene. (Arán-Ais et al., 2018) The (211) facet is the most stable. More densely packed layer can enhance reduction in lower potentials. (Durand et al., 2011) Suggested is to synthesize electrodes with altered structures, as nanoparticles have high surface-to-volume-ratio, more active sites, better catalytic activity. Electrodeposition of copper nanostructures can increase the capacitance 13 times compared to polycrystalline copper. (Díaz-Duque et al., 2015)
Other ways to regulate electrolysis is introducing copper-complexing chemicals (ammonia) or changing the chemical environment, where cationexchange membrane selectively forms ethane, and anion membrane- formaldehyde. (Díaz-Duque et al., 2015)

The main disadvantages of $\mathrm{Cu}$ is its lability, natural oxidation on air exposure and corrosion in aqueous chlorides. The active surface can be protected from oxidation by chemisorption of organic compounds. A densely packed organic barrier is called SAM (selfassembled monolayer). The basis of SAM is to form strong $\mathrm{Cu}-\mathrm{S}$ or $\mathrm{Cu}-\mathrm{N}$ covalent bonds. Many compounds can be used as barriers, like nalkanethiols, 2-mercapto-1,3,4-thiadiazole, ntetradecanoic acid as a super-hydrophobic layer, caffeine, Schiff bases, amino acids, surfactants, leaves extract. (H. Y. Ma et al., 2003; Durainatarajan et al., 2018; T. Liu et al., 2007; Fallavena et al., 2006; Quan et al., 2001; D.-Q. Zhang et al., 2008; H. Ma et al., 2003; Valek et al., 2007; Kear et al., 2004)

Another application of copper was found in chemical oxygen demand (COD) measurement. COD is a marker of water pollution level and is defined as oxygen consumption for oxidation of organic compounds using strong oxidizers. For COD determination standard reagents like glycine or glucose are used. Hassan et al. electrodeposited nanolayer of copper on copper cable and disc electrodes. Constant potential and an alkaline medium were used. Copper oxides formed on the surface mediated oxidation of glycine. The higher oxidation current was achieved with an increase of the $-\mathrm{OH}$ concentration. The main catalyst were $\mathrm{Cu}$ (III) active species. Amperometric detection showed linear range 2-595 mg/L and limit of detection (LOD) $2.6 \mathrm{mg} / \mathrm{L}$. (Hassan et al., 2018)

$\mathrm{Cu}$ is also deliberately used in OLEDs (organic lightemitting devices). (Bizzarri et al., 2018) The technology of ultrathin metal layers deposition on flexible substrates is believed to be an alternative for ITO (indium tin oxide) anodes, as ITO is brittle and indium is considered to be poisonous. Xiong et al. have proposed the atomic layer deposition at low temperature $\left(110^{\circ} \mathrm{C}\right)$ for transparent copper film formulation. Transparent conductive copper film has lower resistivity than aluminum. Continuous and smooth morphology of conductive $\mathrm{Cu}$ was achieved by the ligand-exchange reaction of two complexes: copper dimethylamino-2-propoxide and diethylzinc. Cu thickness was $10 \mathrm{~nm}$ with a $74 \%$ transparency at 
$550 \mathrm{~nm}$ and good conductivity $10.2 \Omega / \mathrm{sq}$. This method gave higher luminance comparing to standard OLEDs and ITO anodes. (Xiong et al., 2018)

\subsubsection{Simple chemical compounds detection}

Copper shows excellent catalytic activity to redox processes of many analytes which are essential from the scientific or industrial point of view. $\mathrm{Cu}$ electrode or CuNPs are willingly used for metals detection (zinc, lead) or other simple inorganic compounds like nitrates in water, $\mathrm{NO}_{2}$ in a gas sensor, glycerol in biodiesel, hydrazine, acetylsalicylic acid, uric acid, urine analysis (determination of tryptophan, acetaminophen and epinephrine), bilirubin and others. (Pei et al., 2014; Kang et al., 2017; Liang et al., 2016; Su et al., 2018; Maruta et al., 2012; Karim-Nezhad et al., 2009; do Socorro Maia Quintino et al., 2002; Sakamoto et al., 2011; Taleb et al., 2018; Noh et al., 2014)

Song et al. have proposed a sensor for hydrogen peroxide $\left(\mathrm{H}_{2} \mathrm{O}_{2}\right)$ reduction based on glassy carbon electrode (GCE) moodifiying it with CuNPs and CuONPs. Copper was electrodeposited from $\mathrm{CuCl}_{2}$ solution at $-0.4 \mathrm{~V}$ for $1 \mathrm{~min}$. The next step was scanning of the electrode in $\mathrm{NaOH}$ by cyclic voltammetry $(\mathrm{CV})$ in the potential range of -0.5 to $0.3 \mathrm{~V}$ for oxidation of CuNPs to CuONPs. Two-steps modification (Cu@CuO/GCE) showed the best activity forward $\mathrm{H}_{2} \mathrm{O}_{2}$ comparing to $\mathrm{CuO} / \mathrm{GCE}$ and bare GCE. The differential pulse voltammetry (DPV) detection exhibited linearity in $0.005-8 \mathrm{mM}$ range. The main advantage of this approach was an enzyme-like activity of Cu@CuO/GCE without using peroxidase, enhancing stability and reproducibility. (H. Song et al., 2015) Other authors also proposed hydrogen peroxide sensors on the carbon substrate. Zhao et al. synthesized Cu@Pt core-shell NPs and deposited onto GCE. Amperometric detection showed a linear range of $0.0005-32.6 \mathrm{mM}$ of $\mathrm{H}_{2} \mathrm{O}_{2}$ and LOD $0.15 \mu \mathrm{M}$. (Zhao et al., 2017) Reddy et al. electrodeposited $\mathrm{Cu} / \mathrm{CuONPs}$ on pencil graphite using ionic and neutral surfactant templates. Amperometric detection showed linearity in the range $1 \mu \mathrm{M}-13 \mathrm{mM}$ of $\mathrm{H}_{2} \mathrm{O}_{2}$ with LOD of $0.35 \pm 0.04$ $\mu \mathrm{M}$. (Reddy et al., 2017) Liu et al. have elaborated glassy carbon- polydopamine sensor (GCE-PDA) with in-situ reduction of CuNPs $(20 \mathrm{~nm})$ from $\mathrm{Cu}(\mathrm{II})$ onto graphene oxide sheets. This approach prevented irreversible aggregation or poor adhesion of NPs on sensor. PDA worked simultaneously as reductant and adhesive for CuNPs. Amperometric detection showed a linear response in $5 \mu \mathrm{M}-12 \mathrm{mM}$
$\mathrm{H}_{2} \mathrm{O}_{2}$ concentration range and $1.4 \mu \mathrm{M}$ detection limit. (Y. Liu et al., 2016)

\subsubsection{Human body analysis application}

Detection of the purines adenine $(A)$ and guanine $(G)$ is crucial for proper organism functioning. Unstable purine content can cause anemia, epilepsy and cancer. Wang et al. formed copper-nickel (Cu@Ni) NPs composite layer onto multiwalled carbon nanotubes (MWCNTs) for purines detection. $\mathrm{Cu} @ \mathrm{Ni}$ was deposited by a droplet and left to dry. Bimetallic NPs were chosen for their synergistic effect and high catalytic activities. The scan range 0.6-1.4 $\mathrm{V}$ and phosphate buffer of $\mathrm{pH}=3$ were established as optimal conditions. Electrochemical pretreatment by $\mathrm{CV}$ before the sensor usage was to prevent NPs aggregation. Linear DPV peaks in ranges of 5-190 $\mu \mathrm{M}($ LOD $0.35 \mu \mathrm{M})$ for $\mathrm{A}$ and $8-150$ $\mu \mathrm{M}(\mathrm{LOD} \quad 0.56 \mu \mathrm{M})$ for $\mathrm{G}$ were obtained in simultaneous detection. The sensor was adequate for real samples from mice brain tissue. (D. Wang et al., 2018) CuNPs have found interest in glucose sensing. The measurement of glucose level is essential in fields as food industry or clinical diagnostics. Alternative enzymatic sensors suffer from poor stability, where enzymes can be deactivated by chemical/thermal treatment. Nonenzymatic NPs-based sensors are a good alternative for sensors commercialization. (Jiaojiao et al., 2015) Song et al. decorated copper foil with $\mathrm{CuO}$ nanoflowers for chronoamperometric glucose detection. Cu foil was used simultaneously as a substrate and $\mathrm{Cu}$ source. Glucose was oxidized under alkaline conditions. Large surface area gave a high sensitivity of $789.3 \mu \mathrm{A} / \mathrm{mM} \cdot \mathrm{cm}^{2}$ and linear detection in range $9.54 \times 10^{-8}-3.13 \times 10^{-3} \mathrm{M}$. (M.-J. Song et al., 2013)

Another non-enzymatic glucose sensor was presented by Lin et al. which electrochemically compared three composites: $\mathrm{CuO}, \mathrm{Cu} / \mathrm{Cu}_{2} \mathrm{O}$, $\mathrm{Cu} / \mathrm{Cu}_{2} \mathrm{O} / \mathrm{CuO}$. Composites were prepared in an aerosol furnace reactor and deposited onto GCE. The sensor showed high selectivity in the presence of human blood interferences: $\mathrm{NaCl}, \mathrm{KCl}, \mathrm{CaCl}_{2}$, ascorbic acid, uric acid, dopamine. The amperometric detection limit of glucose was 0.39 $\mu \mathrm{M}$. The sensitivity was on $8726 \mu \mathrm{A} / \mathrm{mM} \cdot \mathrm{cm}^{2}$ level for $\mathrm{Cu} / \mathrm{Cu}_{2} \mathrm{O} / \mathrm{CuO}$, where only $1104 \mu \mathrm{A} / \mathrm{mM} \cdot \mathrm{cm}^{2}$ for $\mathrm{Cu} / \mathrm{Cu}_{2} \mathrm{O}$ and $1234 \mu \mathrm{A} / \mathrm{mM} \cdot \mathrm{cm}^{2}$ for $\mathrm{CuO}$. The $\mathrm{Cu} / \mathrm{Cu}_{2} \mathrm{O}$ showed the highest electron transfer resistance but weak electrocatalytic efficiency. $\mathrm{Cu} / \mathrm{Cu}_{2} \mathrm{O} / \mathrm{CuO}$ turned out to have low electron transfer resistance, high surface area, thus the 
highest electron transfer ability. (Lin et al., 2018; Fang et al., 2018)

Practical application of copper electrodes was found in alcohol sensing. Measurement of breath alcohol concentration (BrAC) is dominating comparing to blood alcohol concentration (BAC) analysis as it is a non-invasive method. The method validation showed a ratio of BAC:BrAC of 2100:1. (Millet et al., 1996) The electrochemical approach enables realtime analysis, low costs, and miniaturization. Alternative techniques have drawbacks, like high costs and no portability (gas chromatography), poor accuracy (colorimetric tests). The principle of the method is the amperometric measurement of ethanol oxidation on the copper electrode. It is possible due to the mediation of soluble $\mathrm{Cu}$ (III) species generated from $\mathrm{Cu}$ (II) oxide.

Paixão et al. have proposed an alcohol breath sensor. Copper was electrodeposited from $\mathrm{Cu}^{2+}$ solution on platinum disc electrode using constant potential $-0.1 \mathrm{~V}$. Ethanol vapor in the equilibrium with an ethanol solution of different concentrations was pumped into the electrochemical cell. Amperometric detection showed LOD at $0.005 \%$ ethanol concentration level. This method is nonselective in the presence of other organic compounds, however in the breath of people after alcohol consumption they are on relatively low concentrations. (Paixão et al., 2004)

Other essential analytes for health determination are dopamine (DA) and paracetamol (PA), as their abuse have side effects. Devaraj et al. synthesized $\mathrm{Cu} / \mathrm{Cu}_{2} \mathrm{O}-\mathrm{NPs}$ composite for simultaneous detection of DA and PA. The approach of thermal decomposition reaction using a combination of oleylamine and oleic acid gave controlled NPs growth with good shape monodispersity and inhibited NPs oxidation, confirmed by X-ray studies. The $\mathrm{Cu} / \mathrm{Cu}_{2} \mathrm{O} / \mathrm{MWCNTs} / \mathrm{GCE}$ sensor showed enhancement and $200 \mathrm{mV}$ separation of oxidation current peaks of PA and DA where bare GCE did not show any meaningful response. DPV measurements gave linearity for DA in range 0.02 $0.159 \mu \mathrm{M}\left(\mathrm{R}^{2}=0.989\right)$ with a sensitivity of 22.87 $\mu \mathrm{A} / \mu \mathrm{M}$ and LOD of $3.27 \mathrm{nM}$. For PA, linearity was at 1-142.9 $\mu \mathrm{M}$ concentration level $\left(R^{2}=0.998\right)$ with a sensitivity of $0.026 \mu \mathrm{A} / \mu \mathrm{M}$ and LOD of $1.51 \mu \mathrm{M}$. Interferential ascorbic acid showed a separate oxidation peak at $-0.14 \mathrm{~V}$ and did not interfere with analytes. (Devaraj et al., 2016)

Very interesting research of Chen et al. showed $\mathrm{CuO}$ nanowires/single-walled CNTs composite applied onto GCE as DNA sensor. After GCE modification three incubation steps were performed: single-stranded DNA linkage by amide bonds to the substrate, complementary single-stranded DNA hybridization, and Adriamycin incubation, which worked as an electrochemical indicator. The DPV peak current of Adriamycin corresponded to the logarithm of double-stranded DNA. Linearity range was $1 \times 10^{-14}-1 \times 10^{-8} \mathrm{M}$ with LOD of $3.5 \times 10^{-15} \mathrm{M}$. (Chen et al., 2016)

Zen et al. decorated screen-printed carbon electrode (SPCE) with CuNPs for the determination of native 20 amino acids (AA). Authors have used the chronoamperometric method with flow injection analysis. AA were detected at zero potential (vs. $\mathrm{Ag} / \mathrm{AgCl})$ in a phosphate buffer solution $(\mathrm{pH}=8)$. The SPCE rich in $\mathrm{CuO} / \mathrm{Cu}_{2} \mathrm{O}$ species worked as a redox pair and turned out to be sensitive to analytes, as $\mathrm{Cu}_{x} \mathrm{O}-\mathrm{AA}$ electroactive complexes were formed and detected. A linear response was in the range of 24 $\mathrm{nM}-2.7 \mathrm{mM}$. (Zen et al., 2004)

\subsubsection{Other applications}

As copper can be transformed into various formsfoils, conductive patternable nanofibers, elastic transparent and tensile strain materials thus have found application in different types of sensors. (Xu et al., 2005; Jo et al., 2017; Hu et al., 2014) Known are water content sensor for fire resistance tests of cement and concrete or electronic tongue measuring electric resistance for distinguishing types of wines and whiskeys. (Lee et al., 2018; Novakowski et al., 2011) As copper is highly conductive, it can be used as an electrode for the SmartSkin- capacitive sensor for interactive surfaces reacting on human hand touch and move. (Rekimoto, 2002) Cu can also be utilized in the ionselective electrode for potentiometric $\mathrm{Cu}(\mathrm{II})$ and iodide determination down to $1 \times 10^{-5} \mathrm{~mol} / \mathrm{L}$ concentrations. (Dobčnik et al., 1999)

The high surface-to-volume ratio and reactivity of CuNPs occurred in the antimicrobial properties. They can deactivate viruses- influenza, HIV, bacteria- Staphylococcus aureus, Escherichia coli and fungi- Saccharomyces cerevisiae. (Noyce et al., 2007; Borkow et al., 2008; Różańska et al., 2017; Wilks et al., 2005; Cioffi et al., 2005) The efficiency depends on parameters like temperature, humidity or copper structure. (Vincent et al., 2016) Copper disinfection properties have applications in water treatment, working surfaces or textiles. (Gitis et al., 2018; Parra et al., 2018; Marcus et al., 2017) 
A very interesting application of CuNPs was shown by Qiao et al. in a fluorescent $\mathrm{pH}$ sensor. Chicken egg white copper nanoclusters were developed in one-step synthesis by mixing reagents in alkaline solutions at $55^{\circ} \mathrm{C}$. Chicken egg white has a high content of proteins $(10 \% \mathrm{w} / \mathrm{w})$ which controls the growth and nucleation of NPs. Nanoclusters formulation was confirmed by fluorescence spectrum with strong emission at $417 \mathrm{~nm}$ and excitation at $337 \mathrm{~nm}$. Good linearity $\left(R^{2}=0.9933\right)$ was achieved in $\mathrm{pH}$ range from 6.14 to 12.08 in Britton-Robinson buffers solutions. The sensor showed great stability up to two months. (Qiao et al., 2015)

Aparna et al. have used polyethylene imine capped copper nanoclusters for trinitrotoluene (TNT) colorimetric and fluorescent detection. Nanoclusters were synthesized by a one-pot microwave method and showed a blue emission at $480 \mathrm{~nm}$. The fluorescent approach utilized vapor phase detection with a LOD of $0.05 \mathrm{nM}$ of TNT. Spectrophotometric detection gave LOD of 14 pM of TNT. (Aparna et al., 2018)

\section{Conclusions with the future outlook}

The key issues connected to the copper metal electrochemical characteristic and its implementation in biochemical sensing were presented. Its scientific interest derives from good electrical and thermal properties. It turned out that nanoforms of $\mathrm{Cu}$ have high catalytic activity towards many analytes like metals, nitrates or enzyme-like properties in hydrogen peroxide sensing. Demonstration of the copper detector for industrial branches proves its essential role in the environmental sector for COD monitoring or $\mathrm{CO} 2$ concentration reduction.

Fortunately, the major challenges connected to the high activity and unfavorable oxidation of Cu surface were overcome. Through the control of parameters of $\mathrm{Cu}$ nanoforms growth like potential, deposition time, the nanoparticles shapes and sizes are strictly defined. Oxidation issue can be easily overcome by SAM forming using $n$-alkanethiols, caffeine, amino acids.

The copper electrode was found favorable for many of major electrochemical techniques, like CV, DPV, amperometry. It is difficult to choose a proper technique for Cu-based sensors, as many of them are used simultaneously for sensors characterization. For the highest sensitivities (lowest LODs) DPV is commonly used in DNA detection, where for continuous measurements amperometry is most practical for glucose sensing.

The hopes in the future Cu-based sensing are in its low costs, high activity, and natural abundance. Copper brings simplicity, effectiveness, and cost savings of analyzes. Currently developed prototypes like SmartSkin, electronic tongues or already commercialized OLEDs are the clue for the future diagnostic or hi-tech solutions.

\section{Author contributions}

KD, WB, NM made literature research, prepared an original draft and wrote the manuscript. EC, DN edited and supervised the work.

\section{Conflict of interest}

The authors declare no conflict of interest.

\section{Funding}

This publication was supported by the National Centre for Research and Development (NCBR) TECHMATSTRATEG1/347324/12/NCBR/2017;

VENTURES program of the Foundation for Polish Science, co-financed by the European Union, Regional Development Fund; the project "Research and development work on an innovative, ultrasensitive, fast and cheap micro-test for detecting the influenza virus - FLUSENSOR" (RPMA.01.02.0014-6231/16) as part of action 1.2 "Enterprise R\&D activity" of the Regional Operational Programme of Mazowieckie Voivodeship for 2014-2020, cofinanced by the European Regional Development Fund, Priority Axis I "Use of R\&D activity in economy"; and the project "Research and development works to develop a MULTISENSOR prototype - an innovative micro-sensor for identifying bacterial or viral causes of upper respiratory tract infections" as part of action 1.1 "Enterprise R\&D projects" sub-action 1.1.1 "Industrial research and development activities carried out by enterprises" of the Smart Growth Operational Programme 2014-2020, co-financed by the funds from the European Regional Development Fund. 


\section{References:}

Liu S., Li Y., Ta N., Zhou Y., Wu Y., Li M., and Shen W. (2018); Fabrication of palladium-copper nanoparticles with controllable size and chemical composition; J. Colloid Interface Sci.; 526; 201-206

Li C., Yamahara H., Lee Y., Tabata H., and Delaunay J.-J. (2015); CuO nanowire/microflower/nanowire modified $\mathrm{Cu}$ electrode with enhanced electrochemical performance for nonenzymatic glucose sensing; Nanotech.; 26(30); 305503

Singh S., Maheshwari S., and Pandey, P. C. (2004); Some investigations into the electric discharge machining of hardened tool steel using different electrode materials; J. Mater. Process. Technol.; 149(1); 272-277

Reske R., Mistry H., Behafarid F., Roldan Cuenya B., and Strasser P. (2014); Particle Size Effects in the Catalytic Electroreduction of $\mathrm{CO}_{2}$ on $\mathrm{Cu}$ Nanoparticles. J. Am. Chem. Soc.; 136(19); 6978-6986

Sahai A., Goswami N., Kaushik S. D., and Tripathi S. (2016); $\mathrm{Cu} / \mathrm{Cu}_{2} \mathrm{O} / \mathrm{CuO}$ nanoparticles: Novel synthesis by exploding wire technique and extensive characterization; Appl. Surf. Sci.; 390; 974-983

Zuo Y., Shen J., Xu H., and Gao R. (2017); Effect of different sizes of $\mathrm{Cu}$ nanoparticles on the shear strength of Cu-Cu joints; Mater. Lett.; 199; 13-16

Dang R., Jia X., Liu X., Ma H., Gao H., and Wang G. (2017); Controlled synthesis of hierarchical Cu nanosheets @ CuO nanorods as highperformance anode material for lithium-ion batteries. Nano Energy; 33; 427-435

Tran N.-H., Duong T.-H., and Kim H.-C. (2017); A fast fabrication of copper nanowire transparent conductive electrodes by using pulsed laser irradiation; Sci. Rep.; 7(1); 15093

Guo H., Chen Y., Cortie M. B., Liu X., Xie Q., Wang X., and Peng D.-L. (2014); ShapeSelective Formation of Monodisperse Copper Nanospheres and Nanocubes via Disproportionation Reaction Route and Their Optical Properties; J. Phys. Chem. C; 118(18); 9801-9808
Tamilvanan A., Balamurugan K., Ponappa K., and Kumar B. M. (2014); Copper Nanoparticles: Synthetic Strategies, Properties and Multifunctional Application; Int. J. Nanosci.; 13(02); 1430001

Wu C.-J., Chen S.-M., Sheng Y.-J., and Tsao H.-K. (2014); Anti-oxidative copper nanoparticles and their conductive assembly sintered at room temperature; J. Taiwan Inst. Chem. Eng.; 45(5); 2719-2724.

Balasubramanian P., Velmurugan M., Chen S.-M., and Hwa K.-Y. (2017); Optimized electrochemical synthesis of copper nanoparticles decorated reduced graphene oxide: Application for enzymeless determination of glucose in human blood; J. Electroanal. Chem.; 807; 128-136

Yang C.-J., and Lu F.-H. (2013); Shape and Size Control of $\mathrm{Cu}$ Nanoparticles by Tailoring the Surface Morphologies of TiN-Coated Electrodes for Biosensing Applications; Langmuir; 29(51); 16025-16033

Anand V., Harshavardhan, and Srivastava, V. C. (2015); Synthesis and Characterization of Copper Nanoparticles by Electrochemical Method: Effect of pH; JNanoR; 31; 81-92

Huang L., Lee E.-S., and Kim K.-B. (2005); Electrodeposition of monodisperse copper nanoparticles on highly oriented pyrolytic graphite electrode with modulation potential method; Colloids Surf., A; 262(1); 125-131

Salehi S. (2014); Influence of $\mathrm{pH}$ on the Electrochemical Deposition of Composite Coatings in Copper Matrix with $\mathrm{TiO}_{2}$ Nanoparticles; Optics; 3(1); 1-4

Zhang Q. B., and Hua Y. X. (2014); Electrochemical synthesis of copper nanoparticles using cuprous oxide as a precursor in choline chloride-urea deep eutectic solvent: nucleation and growth mechanism; Phys. Chem. Chem. Phys.; 16(48); 27088-27095

Xie Y., Song Y., Zhang Y., Xu L., Miao L., Peng C., and Wang L. (2018); Cu metal-organic framework-derived

$\mathrm{Cu}$ Nanospheres@Porous

carbon/macroporous carbon for electrochemical sensing glucose; J. Alloys Compd.; 757; 105-111 
Jin L., He G., Xue J., Xu T., and Chen H. (2017); $\mathrm{Cu} /$ graphene with high catalytic activity prepared by glucose blowing for reduction of p-nitrophenol; J. Clean. Prod.; 161; 655662

Wang S., Han S., Xin G., Lin J., Wei R., Lian J., and Yu Q. (2018); High-quality graphene directly grown on $\mathrm{Cu}$ nanoparticles for $\mathrm{Cu}$ graphene nanocomposites; Mater. Des.; 139; 181-187

Lassègue P., Noé L., Monthioux M., and Caussat, B. (2017); Fluidized bed chemical vapor deposition of copper nanoparticles on multi-walled carbon nanotubes; Surf. Coat. Technol.; 331; 129-136

Tahir M. A., Bajwa S. Z., Mansoor S., Briddon R. W., Khan W. S., Scheffler B. E., and Amin I. (2018); Evaluation of carbon nanotube based copper nanoparticle composite for the efficient detection of agroviruses; $\mathrm{J}$. Hazard. Mater.; 346; 27-35

Arévalo F. J., Osuna-Sánchez Y., Sandoval-Cortés J., Di Tocco A., Granero A. M., Robledo S. N., and Fernández H. (2017); Development of an electrochemical sensor for the determination of glycerol based on glassy carbon electrodes modified with a copper oxide nanoparticles/multiwalled carbon nanotubes/pectin composite; Sens. Actuators, B; 244; 949-957

Ma X., Qi K., Wei S., Zhang L., and Cui X. (2019); In situ encapsulated nickel-copper nanoparticles in metal-organic frameworks for oxygen evolution reaction; J. Alloys Compd.; 770; 236-242

Shah A., Akhtar M., Aftab S., Shah A. H., and Kraatz H.-B. (2017); Gold copper alloy nanoparticles (Au-Cu NPs) modified electrode as an enhanced electrochemical sensing platform for the detection of persistent toxic organic pollutants; Electrochim. Acta; 241; 281-290

Marioli J. M., and Kuwana T. (1992); Electrochemical characterization of carbohydrate oxidation at copper electrodes; Electrochim. Acta; 37(7); 11871197

Paixão T. R. L. C., and Bertotti M. (2004); Development of a breath alcohol sensor using a copper electrode in an alkaline medium; J. Electroanal. Chem.; 571(1); 101-109

Rendón-Calle A., Builes S., \& Calle-Vallejo F. (2018); A brief review of the computational modeling of $\mathrm{CO}_{2}$ electroreduction on $\mathrm{Cu}$ electrodes; Curr. Opin. Electrochem.; 9; 158-165

Hori Y., Murata A., Takahashi R., and Suzuki S. (1987); Electroreduction of carbon monoxide to methane and ethylene at a copper electrode in aqueous solutions at ambient temperature and pressure; $\mathrm{J}$. Amer. Chem. Soc.; 109(16); 5022-5023

Jitaru M., Lowy D. A., Toma M., Toma B. C., and Oniciu L. (1997); Electrochemical reduction of carbon dioxide on flat metallic cathodes; J. Appl. Electrochem.; 27(8); 875-889

Han S., Hong S., Yeo J., Kim D., Kang B., Yang M.Y., and Ko S. H. (2015); Nanorecycling: Monolithic Integration of Copper and Copper Oxide Nanowire Network Electrode through Selective Reversible Photothermochemical Reduction; $A d v$. Mater.; 27(41); 6397-6403

Durand W. J., Peterson A. A., Studt F., AbildPedersen F., and Nørskov J. K. (2011); Structure effects on the energetics of the electrochemical reduction of $\mathrm{CO}_{2}$ by copper surfaces; Surf. Sci.; 605(15); 13541359

Garza A. J., Bell A. T., and Head-Gordon M. (2018); Mechanism of $\mathrm{CO}_{2}$ Reduction at Copper Surfaces: Pathways to $\mathrm{C}_{2}$ Products; ACS Catalysis; 8(2); 1490-1499

Liu C., Cundari T. R., and Wilson A. K. (2012); $\mathrm{CO}_{2}$ Reduction on Transition Metal (Fe, Co, Ni, and $\mathrm{Cu}$ ) Surfaces: In Comparison with Homogeneous Catalysis; J. Phys. Chem. C; 116(9); 5681-5688

Arán-Ais R. M., Gao D., and Roldan Cuenya B. (2018); Structure- and ElectrolyteSensitivity in $\mathrm{CO}_{2}$ Electroreduction;. Acc. Chem. Res.; 51(11); 2906-2917

Díaz-Duque Á., Sandoval-Rojas A. P., MolinaOsorio A. F., Feliu J. M., and SuárezHerrera M. F. (2015); Electrochemical reduction of $\mathrm{CO}_{2}$ in water-acetonitrile mixtures on nanostructured $\mathrm{Cu}$ electrode; Electrochem. Commun.; 61; 74-77 
Ma H. Y., Yang C., Yin B. S., Li G. Y., Chen S. H., and Luo J. L. (2003); Electrochemical characterization of copper surface modified by $\mathrm{n}$-alkanethiols in chloride-containing solutions; Appl. Surf. Sci.; 218(1); 144-154

Durainatarajan P., Prabakaran M., Ramesh S., and Periasamy V. (2018); Corrosion Protection of Copper in $3 \% \mathrm{NaCl}$ Solution by the Fabrication of Thiadiazole Monolayer; J. Nanosci. Nanotechnol.; 18(8); 5414-5422

Liu T., Yin Y., Chen S., Chang X., and Cheng S. (2007); Super-hydrophobic surfaces improve corrosion resistance of copper in seawater; Electrochim. Acta; 52(11); 37093713

Fallavena T., Antonow M., and Gonçalves R. S. (2006); Caffeine as non-toxic corrosion inhibitor for copper in aqueous solutions of potassium nitrate; Appl. Surf. Sci.; 253(2); 566-571

Quan Z., Wu X., Chen S., Zhao S., and Ma H. (2001); Self-Assembled Monolayers of Schiff Bases on Copper Surfaces; Corrosion; 57(3); 195-201

Zhang D.-Q., Cai Q.-R., He X.-M., Gao L.-X., and Zhou G.-D. (2008); Inhibition effect of some amino acids on copper corrosion in $\mathrm{HCl}$ solution; Mater. Chem. Phys.; 112; 353358

Ma H., Chen S., Yin B., Zhao S., and Liu X. (2003); Impedance spectroscopic study of corrosion inhibition of copper by surfactants in the acidic solutions; Corros. Sci.; 45(5); 867-882

Valek L., and Martinez S. (2007); Copper corrosion inhibition by Azadirachta indica leaves extract in $0.5 \mathrm{M}$ sulphuric acid; Mater. Lett; 61(1); 148-151

Kear G., Barker B. D., and Walsh F. C. (2004); Electrochemical corrosion of unalloyed copper in chloride media-a critical review; Corros. Sci.; 46(1); 109-135

Hassan H. H., Badr I. H. A., Abdel-Fatah H. T. M., Elfeky E. M. S., and Abdel-Aziz A. M. (2018); Low cost chemical oxygen demand sensor based on electrodeposited nanocopper film;. Arab. J. Chem.; 11(2); 171180
Bizzarri C., Spuling E., Knoll D. M., Volz D., and Bräse S. (2018); Sustainable metal complexes for organic light-emitting diodes (OLEDs); Coord. Chem. Rev.; 373; 49-82

Xiong P., Liu Y., Ding T., Chen P., Wang H., and Duan Y. (2018); Transparent electrodes based on ultrathin/ultra smooth $\mathrm{Cu}$ films produced through atomic layer deposition as new ITO-free organic light-emitting devices; Org. Electron,; 58; 18-24

Pei X., Kang W., Yue W., Bange A., Heineman W. R., and Papautsky I. (2014); Disposable Copper-Based Electrochemical Sensor for Anodic Stripping Voltammetry; Anal. Chem.; 86(10); 4893-4900

Kang W., Pei X., Rusinek C. A., Bange A., Haynes E. N., Heineman W. R., and Papautsky I. (2017); Determination of Lead with a Copper-Based Electrochemical Sensor; Anal. Chem.; 89(6); 3345-3352

Liang J., Zheng Y., and Liu Z. (2016); Nanowirebased $\mathrm{Cu}$ electrode as electrochemical sensor for detection of nitrate in water;. Sens. Actuators, B; 232; 336-344

Su Z., Tan L., Yang R., Zhang Y., Tao J., Zhang N., and Wen F. (2018); Cu-modified carbon spheres/reduced graphene oxide as a high sensitivity of gas sensor for $\mathrm{NO}_{2}$ detection at room temperature; Chem. Phys. Lett.; 695; 153-157

Maruta A. H., and Paixão T. R. L. C. (2012); Flow injection analysis of free glycerol in biodiesel using a copper electrode as an amperometric detector; Fuel; 91(1); 187191

Karim-Nezhad G., Jafarloo R., and Dorraji P. S. (2009); Copper (hydr)oxide modified copper electrode for electrocatalytic oxidation of hydrazine in alkaline media; Electrochim. Acta; 54(24); 5721-5726

do Socorro Maia Quintino M., Corbo D., Bertotti M., and Angnes L. (2002); Amperometric determination of acetylsalicylic acid in drugs by batch injection analysis at a copper electrode in alkaline solutions; Talanta; 58(5); 943-949

Sakamoto H., Hatsuda R., Miyamura K., Shiraishi H., and Sugiyama S. (2011); Electrochemical Selective Detection of Uric 
Acid Using a Copper-modified Carbon Electrode; Anal. Sci.; 27(3); 333-335

Taleb M., Ivanov R., Bereznev S., Kazemi S. H., and Hussainova I. (2018); Alumina/graphene/Cu hybrids as highly selective sensor for simultaneous determination of epinephrine, acetaminophen and tryptophan in human urine; J. Electroanal. Chem.; 823; 184192

Noh H.-B., Won M.-S., and Shim Y.-B. (2014); Selective nonenzymatic bilirubin detection in blood samples using a Nafion/Mn-Cu sensor; Biosens. Bioelectron.; 61; 554-561

Song H., Ni Y., and Kokot S. (2015); A novel electrochemical sensor based on the copper-doped copper oxide nano-particles for the analysis of hydrogen peroxide; Colloids Surf., A; 465; 153-158

Zhao W., Jin J., Wu H., Wang S., Fneg C., Yang S., and Ding Y. (2017); Electrochemical hydrogen peroxide sensor based on carbon supported Cu@Pt core-shell nanoparticles; Mater. Sci. Eng., C; 78; 185-190

Reddy G. R. K., Hyder M., and Kumar P. S. (2017); Facile Preparation of High-Performance Copper Oxide Sensors for Electroanalysis of Hydrogen Peroxide; Mater. Today Proc.; 4(13); 12457-12469

Liu Y., Han Y., Chen R., Zhang H., Liu S., and Liang F. (2016); In situ Immobilization of Copper Nanoparticles on Polydopamine Coated Graphene Oxide for $\mathrm{H}_{2} \mathrm{O}_{2}$ Determination; PLOS ONE; 11(7); e0157926

Wang D., Huang B., Liu J., Guo X., Abudukeyoumu G., Zhang Y., and Li Y. (2018); A novel electrochemical sensor based on Cu@Ni/MWCNTs nanocomposite for simultaneous determination of guanine and adenine; Biosens. Bioelectron; 102; 389395

Jiaojiao J., Yangyang G., Gangying Z., Yanping C., Wei L., and Guohua H. (2015); D-glucose, D-galactose, and D-lactose non-enzyme quantitative and qualitative analysis method based on Cu foam electrode; Food Chem.; 175; 485-493
Song M.-J., Lee S.-K., Kim J.-H., and Lim D.-S. (2013); Non-Enzymatic Glucose Sensor Based on $\mathrm{Cu}$ Electrode Modified with $\mathrm{CuO}$ Nanoflowers; J. Electrochem. Soc.; 160(4); B43-B46

Lin L.-Y., Karakocak B. B., Kavadiya S., Soundappan T., and Biswas P. (2018); A highly sensitive non-enzymatic glucose sensor based on $\mathrm{Cu} / \mathrm{Cu}_{2} \mathrm{O} / \mathrm{CuO}$ ternary composite hollow spheres prepared in a furnace aerosol reactor; Sens. Actuators, B; 259; 745-752

Fang Y., Wang S., Liu Y., Xu Z., Zhang K., and Guo Y. (2018); Development of Cu nanoflowers modified the flexible needle-type microelectrode and its application in continuous monitoring glucose in vivo; Biosens. Bioelectron.; 110; 44-51

Millet P., Michas A., and Durand R. (1996); A solid polymer electrolyte-based ethanol gas sensor;. J. Appl. Electrochem.; 26(9); 933937

Devaraj M., R S., Deivasigamani R., Gupta V., Gracia F., and Jayadevan S. (2016); Preparation of novel shape $\mathrm{Cu}$ and $\mathrm{Cu} / \mathrm{Cu}_{2} \mathrm{O}$ nanoparticles for the determination of dopamine and paracetamol; J. Mol. Liq.; 221

Chen M., Hou C., Huo D., Yang M., and Fa H. (2016); An ultrasensitive electrochemical DNA biosensor based on a copper oxide nanowires/single-walled carbon nanotubes nanocomposite; Appl. Surf. Sci.; 364; 703709

Zen J.-M., Hsu C.-T., Kumar A. S., Lyuu H.-J., and Lin K.-Y. (2004); Amino acid analysis using disposable copper nanoparticle plated electrodes; Analyst; 129(9); 841-845

Xu M., and Dewald H. (2005);. Impedance studies of copper foil and graphite-coated copper foil electrodes in lithium-ion battery electrolyte; Electrochim. Acta; 50; 54735478

Jo H. S., An S., Lee J.-G., Park H. G., Al-Deyab S. S., Yarin A. L., and Yoon S. S. (2017); Highly flexible, stretchable, patternable, transparent copper fiber heater on a complex 3D surface; NPG Asia Materials; 9(2); e347 
Hu W., Wang R., Lu Y., and Pei Q. (2014); An elastomeric transparent composite electrode based on copper nanowires and polyurethane; J. Mater. Chem. C; 2(7); 1298-1305

Lee J., Harada K., and Kwon Y. (2018); Development of water content sensor composed of small copper electrodes for use during fire resistance tests of concrete and cement mortar elements; Fire Mater.; 42(1); 88-98

Novakowski W., Bertotti M., and Paixão T. R. L. C. (2011); Use of copper and gold electrodes as sensitive elements for fabrication of an electronic tongue: Discrimination of wines and whiskies; Microchem. J.; 99(1); 145151

Rekimoto J. (2002); SmartSkin: An Infrastructure for Freehand Manipulation on Interactive Surfaces, CHI Letters; 4(1): 113-120

Dobčnik D., Kolar M., Komljenović J., and Radić N. (1999); Preparation of an ion-selective electrode by chemical treatment of copper wire for the measurement of copper(II) and iodide by batch and flow-injection potentiometry; Fresenius J. Anal. Chem.; 365(4); 314-319

Noyce, J. O., Michels, H., \& Keevil, C. W. (2007); Inactivation of Influenza A Virus on Copper versus Stainless Steel Surfaces. Appl. Environ. Microbiol.; 73(8); 2748-2750

Borkow G., Lara H. H., Covington C. Y., Nyamathi A., and Gabbay J. (2008); Deactivation of Human Immunodeficiency Virus Type 1 in Medium by Copper Oxide-Containing Filters; Antimicrob. Agents Chemother.; 52(2); 518-525

Różańska A., Chmielarczyk A., Romaniszyn D., Sroka-Oleksiak A., Bulanda M., Walkowicz M., and Knych T. (2017); Antimicrobial Properties of Selected Copper Alloys on Staphylococcus aureus and Escherichia coli in Different Simulations of Environmental Conditions: With vs. without Organic Contamination; Int. J. Env. Res. Pub. He.; 14(7); 813

Wilks S. A., Michels H., and Keevil C. W. (2005); The survival of Escherichia coli 0157 on a range of metal surfaces; Int. J. Food Microbiol.; 105(3); 445-454
Cioffi N., Torsi L., Ditaranto N., Tantillo G., Ghibelli L., Sabbatini L., and Traversa E. (2005); Copper Nanoparticle/Polymer Composites with Antifungal and Bacteriostatic Properties; Chem. Mater.; 17(21); 52555262

Vincent M., Hartemann P., and Engels-Deutsch M. (2016); Antimicrobial applications of copper; Int. J. Hyg. Environ. Health; 219(7,A); 585-591

Gitis V., and Hankins N. (2018); Water treatment chemicals: Trends and challenges. JWPE; 25; 34-38

Parra A., Toro M., Jacob R., Navarrete P., Troncoso M., Figueroa G., and Reyes-Jara A. (2018); Antimicrobial effect of copper surfaces on bacteria isolated from poultry meat; Braz. J. Microbiol.; 49(1); 113-118

Marcus E.-L., Yosef H., Borkow G., Caine Y., Sasson A., and Moses A. E. (2017); Reduction of health care-associated infection indicators by copper oxideimpregnated textiles: Crossover, doubleblind controlled study in chronic ventilatordependent patients; Am J. Infect. Control.; 45(4); 401-403

Qiao Y., Xu T., Zhang Y., Zhang C., Shi L., Zhang G., and Dong C. (2015); Green synthesis of fluorescent copper nanoclusters for reversible $\mathrm{pH}$-sensors; Sens. Actuators, $B$; 220; 1064-1069

Aparna R. S., Anjali Devi J. S., Sachidanandan P., and George S. (2018); Polyethylene imine capped copper nanoclusters- fluorescent and colorimetric onsite sensor for the trace level detection of TNT; Sens. Actuators, B; $254 ; 811-819$ 